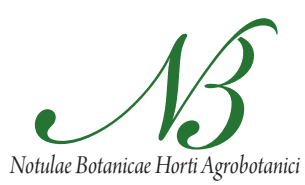

Cluj-Napoca

\title{
Evaluation of Hydrolytic Activity of Different Pectinases on Sugar Beet (Beta vulgaris) Substrate Using FT-MIR Spectroscopy
}

\author{
Adina CHIȘ', Florinela FETEA² ${ }^{2}$ Horea MATEI', Carmen SOCACIU²* \\ ${ }^{1}$ University of Medicine and Pharmacy "I. Hațieganu", Faculty of Medicine, 6 Pasteur Street, Cluj-Napoca, Romania \\ ${ }^{2}$ University of Agricultural Sciences and Veterinary Medicine, Faculty of Agriculture, 3-5 Mănăştur \\ Street, Cluj-Napoca, Romania; casocaciu@usamvcluj.ro (*corresponding author)
}

\begin{abstract}
The aim of this study was to evaluate the pectinase activity of two commercial enzymes Rohament PL and Rohapect 10L, using as substrate the sugar beet pulp, in different conditions. The method applied to check the rate of hydrolysis was Fourier-transformed infrared spectroscopy (FT-MIR), by recording the absorption spectra of different carbohydrates in the specific, MIR (middle IR) spectral range (650-4000 $\left.\mathrm{cm}^{-1}\right)$. In order to calibrate the method, it has been recorded the FT-MIR spectrum of standard solutions of glucose, fructose, sucrose and galacturonic acid, at different concentrations, establishing also the peaks and the fingerprint regions specific to these compounds. Considering the specific peak intensities identified for glucose (at $1033 \mathrm{~cm}^{-1}$ ), fructose (at $1063 \mathrm{~cm}^{-1}$ ), sucrose $($ at $\left.995 \mathrm{~cm}^{-1}\right)$, and based on peak area for galacturonic acid $\left(1500-700 \mathrm{~cm}^{-1}\right)$, it has been calculated their concentrations, as a result of the Rohament PL or Rohapect 10L activity. Based on calibration curves for each sugar type, it has been calculated their concentrations in the sugar beet samples, and after their release by enzymatic treatment, establishing an optimized protocol of action for the two enzymes. Differences among the two enzymes activity were identified, specifically their optimum concentration and hydrolysis timing. FT-MIR spectroscopy proves to be an adequate method to evaluate the enzymatic activity of the different enzyme types, having certain advantages in comparison with the chromatographic methods, being a rapid, non-destructive method, at relatively low costs.
\end{abstract}

Keywords: FT-MIR, hydrolytic enzymes, Rohament PL, Rohapect 10L, sugar beet

\section{Introduction}

Sugar beet (Beta vulgaris) is a plant of the genus Beta, and a member of the family Chenopodiaceae. Sugar beet pulp is especially rich in polysaccharides, such as cellulose (20-24\%), hemicellulose (25-36\%) and pectic substances (15-25\%) (Thibault et al., 1990). The chemical analysis of sugar beet pulp showed that beet pectins differ from apple and citrus pectins by their higher rhamnose content, by the presence of acetyl groups and by the presence of ferulic acid, one of the major phenolic acids found in plant cell walls (Micard et al., 1996). The pectin substances in plant cell walls are found mainly in two regions: a "hairy" rhamnogalacturonan region (RG) and a "smooth" homogalacturonan region (HGA). Both, RG and HGA regions, consist of a backbone of $\alpha$-(1-4)-linked galacturonic acid residues, partially esterified with methyl group ("smooth" regions) which may be interrupted by "hairy" regions (which contain mainly neutral sugars) (Baciu and Jordening, 2004). In these regions, the galacturonic acid accounts for approximately $54.4-77.9 \%$, the rhamnose for $0.9-3.2 \%$, arabinose for $1.8-12.5 \%$ and galactose for $2.4-8.1 \%$. Also, sugar beet pulp contains $1-2 \%$ lignin, $7-8 \%$ protein and carbohydrates that compose the structural homopolymers (cellulose, hemicelluloses) and pectins such as sucrose, glucose, fructose (Foster et al., 2001).
There are two types of enzymes that catalyze the hydrolysis of the pectic substances from sugar beet pulp: pectolytic enzymes, which react with the "smooth" regions of the pectin (composed of partially methoxylated galacturonic acid) and glycan hydrolases, which hydrolyze glycosidic bonds in the "hairy" pectins regions (Sakamoto et al., 1993). Under enzyme action, the cell wall polysaccharides are solubilized and depolymerized, generating different types of substances, such as monosaccharides, disaccharides, galacturonic acid, etc. (Chiş et al., 2010).

Fourier-transformed infrared spectroscopy (FT-MIR), is a well established technique in chemical analysis, as well as a convinent method employed for sugar determination owing to the strong absorption bands of carbohydrates, but it is relatively uncommon compared with chromatographic or other classical methods. FT-MIR has been used to predict sugar contents in both agricultural and food products (Rambla et al., 1998).

This technique, a non-destructive one was reported successful for the determination of sucrose and glucose (Fernandez and Agosin, 2007; Patz et al., 2004) and the discrimination of red wines, edible oils and beer (Ramasami et al., 2004; Urtubia et al., 2008).

The aim of this study was to evaluate, by FT-MIR spectroscopy, the activity of two different types of commercial pectinases, Rohament PL and Rohapect 10L, under dif- 
100

ferent experimental conditions, using as substrate a sugar beet pulp. The utilization of commercial preparations, instead of purified enzymes, was intended with respect to a possible industrial application.

\section{Materials and methods}

\section{Commercial pectinases}

The commercial enzymes chosen for this study were: Rohament PL and Rohapect 10L, produced of AB Enzymes, Darmstadt, Germany. Rohament PL has higher pectolytic activity, useful for the maceration of fruit and vegetable tissues; it contains almost exclusively polygalacturonase activity with minor pectinesterase activity. Rohapect $10 \mathrm{~L}$ is a commercial enzyme produced by Aspergillus niger, and has pectolytic and arabinase activity. The optimum $\mathrm{pH}$ (3.9) for enzyme activity was achieved by acetate buffer addition (acetic acid $1 \mathrm{~N}, \mathrm{NaOH} 1 \mathrm{~N}$ ).

\section{Sample preparation and enzymatic treatment}

Sugar beet pulp from the common beet Beta vulgaris was provided from Sugar Factory "Zahărul” from Luduş County (Transylvania, North of Romania) and stored at $-20^{\circ} \mathrm{C}$ before analysis.

The unfrozen pulp was cut into small pieces and then chopped in a blender. The puree obtained was divided into 21 aliquots, 9 samples for each type of enzyme used in this study and 3 control samples (one for each incubation time). Each aliquot consisted of $5 \mathrm{~g}$ sugar beet puree and $7 \mathrm{ml}$ acetate buffer, $\mathrm{pH}$ 3.9. The enzymes were added at different concentrations (24, 12 and $2.4 \%)$, using different incubation times ( $30 \mathrm{~min}, 3$ and $24 \mathrm{~h}$ ), as presented in Tab.

Tab. 1. Experimental conditions applied for testing pectinase activity (incubation time, concentration and code)

\begin{tabular}{|c|c|c|c|}
\hline Enzyme & $\begin{array}{c}\text { Incubation } \\
\text { time }\end{array}$ & Concentration & Code \\
\hline \multirow{9}{*}{ Rohament PL } & \multirow{4}{*}{$30 \mathrm{~min}$} & $2,4 \%$ & RPL30min $2,4 \%$ \\
\hline & & $12 \%$ & RPL30min $12 \%$ \\
\hline & & $24 \%$ & RPL30min $24 \%$ \\
\hline & & $2,4 \%$ & RPL3h2,4\% \\
\hline & \multirow{3}{*}{$3 \mathrm{~h}$} & $12 \%$ & RPL3h12\% \\
\hline & & $24 \%$ & RPL3h24\% \\
\hline & & $2,4 \%$ & RPL24h2,4\% \\
\hline & \multirow{2}{*}{$24 \mathrm{~h}$} & $12 \%$ & RPL24h12\% \\
\hline & & $24 \%$ & RPL24h24\% \\
\hline \multirow{9}{*}{ Rohapect 10L } & \multirow{4}{*}{$30 \mathrm{~min}$} & $2,4 \%$ & $\mathrm{R} 10 \mathrm{~L} 30 \mathrm{~min} 2,4 \%$ \\
\hline & & $12 \%$ & $\mathrm{R} 10 \mathrm{~L} 30 \mathrm{~min} 12 \%$ \\
\hline & & $24 \%$ & $\mathrm{R} 10 \mathrm{~L} 30 \mathrm{~min} 24 \%$ \\
\hline & & $2,4 \%$ & R10L3h2,4\% \\
\hline & \multirow{2}{*}{$3 \mathrm{~h}$} & $12 \%$ & R10L3h12\% \\
\hline & & $24 \%$ & R10L3h24\% \\
\hline & \multirow{3}{*}{$24 \mathrm{~h}$} & $2,4 \%$ & R10L24h2,4\% \\
\hline & & $12 \%$ & R10L24h12\% \\
\hline & & $24 \%$ & R10L24h24\% \\
\hline
\end{tabular}

1. All samples were stirred and then incubated for different time at $25^{\circ} \mathrm{C}$. After incubation, samples were centrifuged for $3 \times 15$ minutes at $4000 \mathrm{rpm}$. Tab. 1 sumarizes the preparation of samples and their code.

\section{FT-MIR measurements}

All analyses (on carbohydrate standards and juice supernatants obtained after enzyme hydrolysis) were done using a FT-MIR spectrometer (Shimadzu Prestige 2, spectrometer). Each spectrum was recorded in the MIR region, from 4000 to $650 \mathrm{~cm}^{-1}$, and 64 scans were accumulated for each spectrum using the Horizontal Attenuated Total Reflection (HATR) device.

\section{Calibration curves}

In order to identify the carbohydrate specific fingerprint regions and to calibrate the method, different concentrations of pure, standard solutions of glucose $(1,2,3$, $4,5,10,15,20$ and $25 \mathrm{~g} / 100 \mathrm{ml})$, fructose $(3,4,5,7,10$, $15,20$ and $25 \mathrm{~g} / 100 \mathrm{ml})$, sucrose $(1,2,3,4,5,10,15,20$ and $25 \mathrm{~g} / 100 \mathrm{ml}$ ) and galacturonic acid (20.08, 28.92 and $34.71 \mathrm{~g} / 100 \mathrm{ml}$ ) were analyzed by FT-MIR spectrometry in the same conditions.

\section{Data analysis}

The spectra were processed using the IR solution Software Overview (Shimadzu) and OriginR 7SR1 Software (OriginLab Corporation, Northampton, USA). To calculate quantitatively the glucose, fructose, sucrose and galacturonic acid-like the mainly compound released in the sugar beet juice, it has been considered the calibration curves and it has been applied the curve factor.

\section{Results and discussion}

FT-MIR fingerprints and calibration curves for glucose, fructose, sucrose and galacturonic acid

The FT-MIR spectra $\left(4000-900 \mathrm{~cm}^{-1}\right)$ of aqueous solutions of glucose $(25 \%)$, fructose $(25 \%)$ and sucrose $(25 \%)$ were presented in Fig. 1A. As can be seen, the FT-MIR spectra of these solutions are very well defined and show the specific absorption bands (Fig. 1B) in the fingerprint region.

For glucose, the fingerprint region $\left(1200-900 \mathrm{~cm}^{-1}\right)$ includes characteristic bands, with absorptions at 991, 1033, 1078,1107 and $1149 \mathrm{~cm}^{-1}$, the peak at $1033 \mathrm{~cm}^{-1}$ having the highest absorption. Fructose and sucrose have, also, the same fingerprint region $\left(1200-900 \mathrm{~cm}^{-1}\right)$ : fructose has specific maxima at 966,979,1063, $1082 \mathrm{~cm}^{-1}$, and a specific absorption peak at $1063 \mathrm{~cm}^{-1}$, while sucrose shows specific maxima at 995, 1053 and $1136 \mathrm{~cm}^{-1}$, with a maximum absorption at 1053 and $995 \mathrm{~cm}^{-1}$, in a ratio of $1: 1$.

The FT-MIR spectra and fingerprint region for galacturonic acid were different from glucose, fructose and sucrose spectra, as shown in Fig. 2A. The fingerprint region of galacturonic acid (Fig. 2B) is much larger that the other 

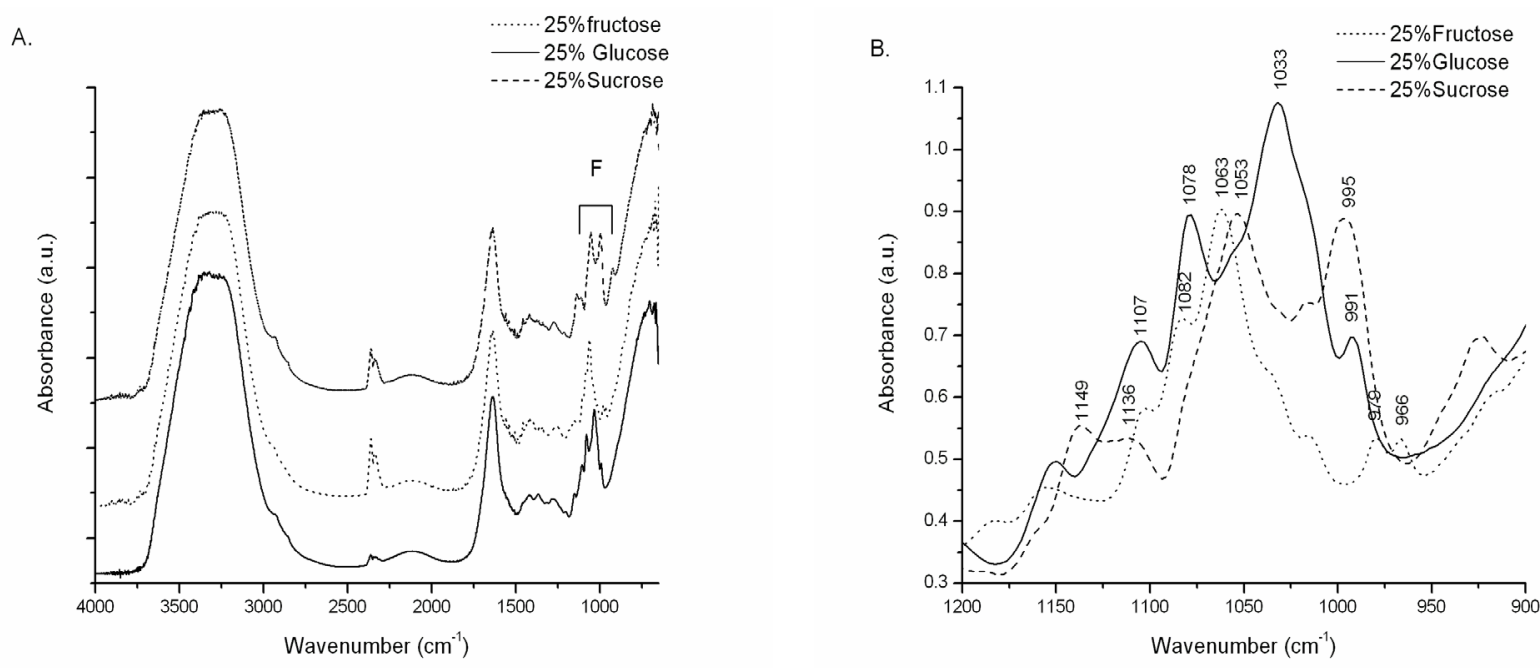

Fig. 1. (A) The integral FT-MIR spectra $\left(4000-900 \mathrm{~cm}^{-1}\right)$ of aqueous standard solutions containing $25 \%$ glucose (solid line), $25 \%$ fructose (dot line) and 25\% sucrose (dash line). (B) Detalied, specific peaks in the fingerprint region (F) $\left(1200-900 \mathrm{~cm}^{-1}\right) \mathrm{of} \mathrm{the}^{-1}$ normalized spectra $\left(1200 \mathrm{~cm}^{-1}\right)$
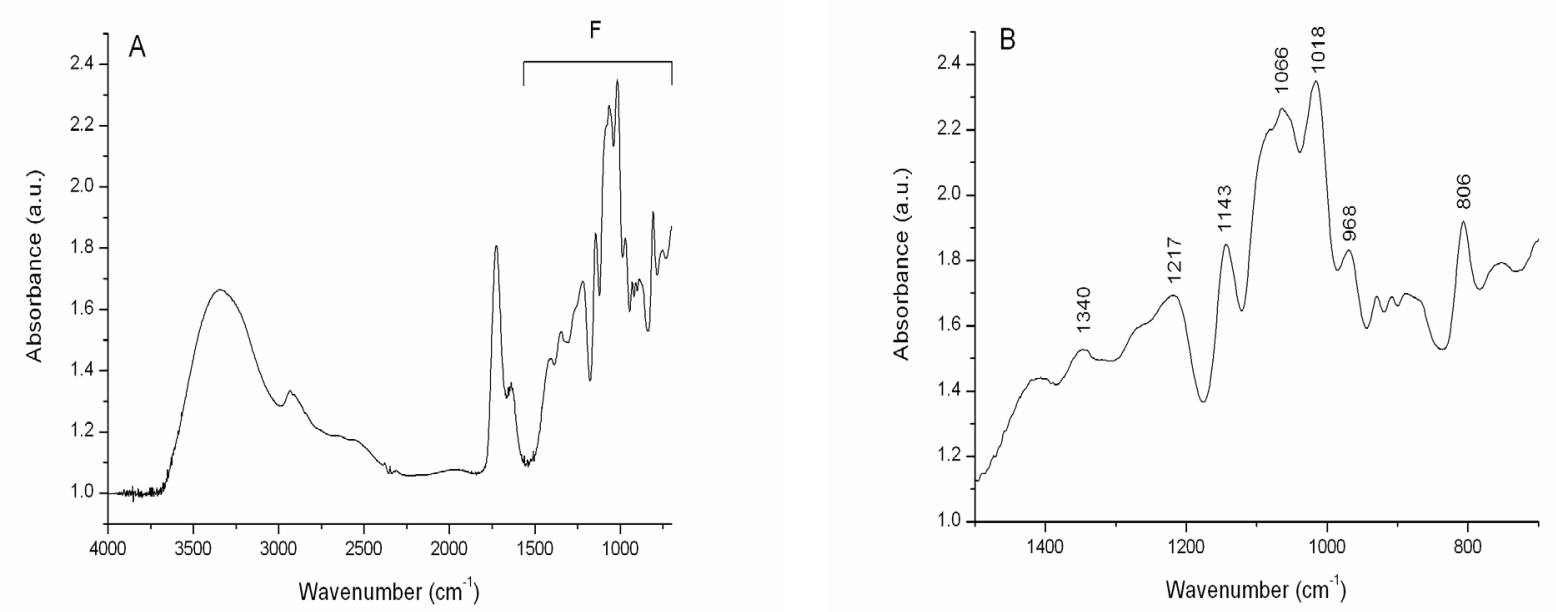

Fig. 2. (A) The integral FT-MIR spectra $\left(4000-700 \mathrm{~cm}^{-1}\right)$ of aqueous standard solution containing $41.66 \%$ galacturonic acid. (B) Specific peaks in the fingerprint region $(F)\left(1500-700 \mathrm{~cm}^{-1}\right)$

carbohydrates, namely $1500-700 \mathrm{~cm}^{-1}$. The specific peaks for galacturonic acid are: 1340, 1217, 1143, 1066, 1018, 968 and $806 \mathrm{~cm}^{-1}$ (Fig. 2B).

The spectral signatures of sugars are somewhat different from each other, as mentioned also by other authors (Max and Chapados, 2007). The most intense peak of glucose $\left(1033 \mathrm{~cm}^{-1}\right)$ is characteristic to the C-O and C-C stretching vibrations, while for fructose or sucrose the most intense peaks appear around 1063, or 1053 and $995 \mathrm{~cm}^{-1}$, respectively. Unlike other simple molecules, sugars have endocyclic and exocyclic C-O bonds, located at $995 \mathrm{~cm}^{-1}$ (exocyclic) for sucrose, and around $1080 \mathrm{~cm}^{-1}$ (endocyclic) for glucose and fructose (Max and Chapados, 2007). The peak of galacturonic acid (located at $1340 \mathrm{~cm}^{-1}$ ) is characteristic to the $\mathrm{CH}_{2}$ bending vibrations, while the 1217 , 1066 and $1018 \mathrm{~cm}^{-1}$ peaks to the $\mathrm{C}-\mathrm{O}$ bending vibrations, while $1143 \mathrm{~cm}^{-1}$ to the C-O-C asymmetric stretching vibra- tions and $968 \mathrm{~cm}^{-1}$ to the $\mathrm{CO}$ symmetric stretching vibrations (Kacurakova et al., 2002).

Based on these data it has been obtained the calibration curves (data not shown), based on the peak intensities for each carbohydrate (glucose, fructose and sucrose) (Chiş et al., 2010) or based on peak areas (for galacturonic acid) in the fingerprint region $\left(1500-700 \mathrm{~cm}^{-1}\right)$. The Calibration curves with pure standards were used in order to determine the glucose, fructose, sucrose and galacturonic acid concentrations in the present samples. The equations and the correlation coefficients for the calibration curves of carbohydrates were: $\mathrm{Abs}=+3.298 \mathrm{E}-1+2.929 \mathrm{E}-2^{*} \mathrm{c}^{\wedge} 1$, $\mathrm{R} 2=0.999282$ for glucose, $\mathrm{Abs}=+3.208 \mathrm{E}-1+2.334 \mathrm{E}$ $2^{*} \mathrm{c}^{\wedge} 1, \quad \mathrm{R} 2=0.998039$ for fructose, Abs $=+3.501 \mathrm{E}-1$ $+2.057 \mathrm{E}-2^{*} \mathrm{c}^{\wedge} 1, \mathrm{R} 2=0.996550$ for sucrose and $\mathrm{y}=2.5999 \mathrm{x}$ $47.131, \mathrm{R} 2=0.9968$ for galacturonic acid. 

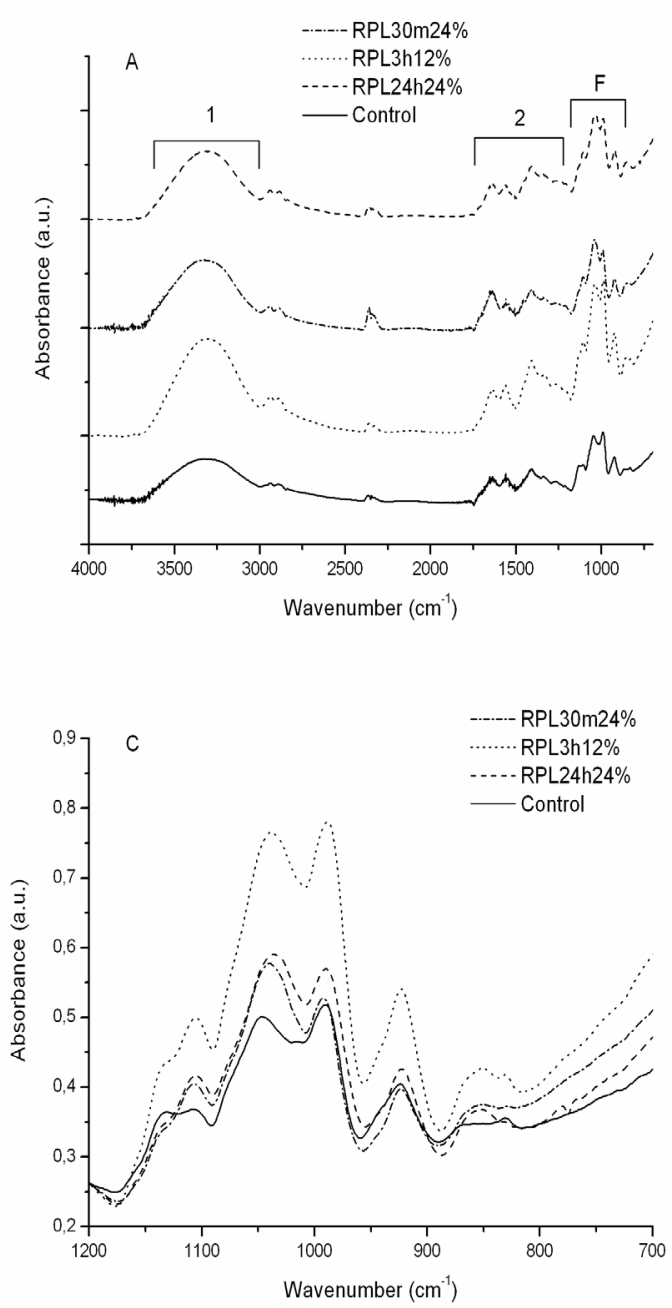
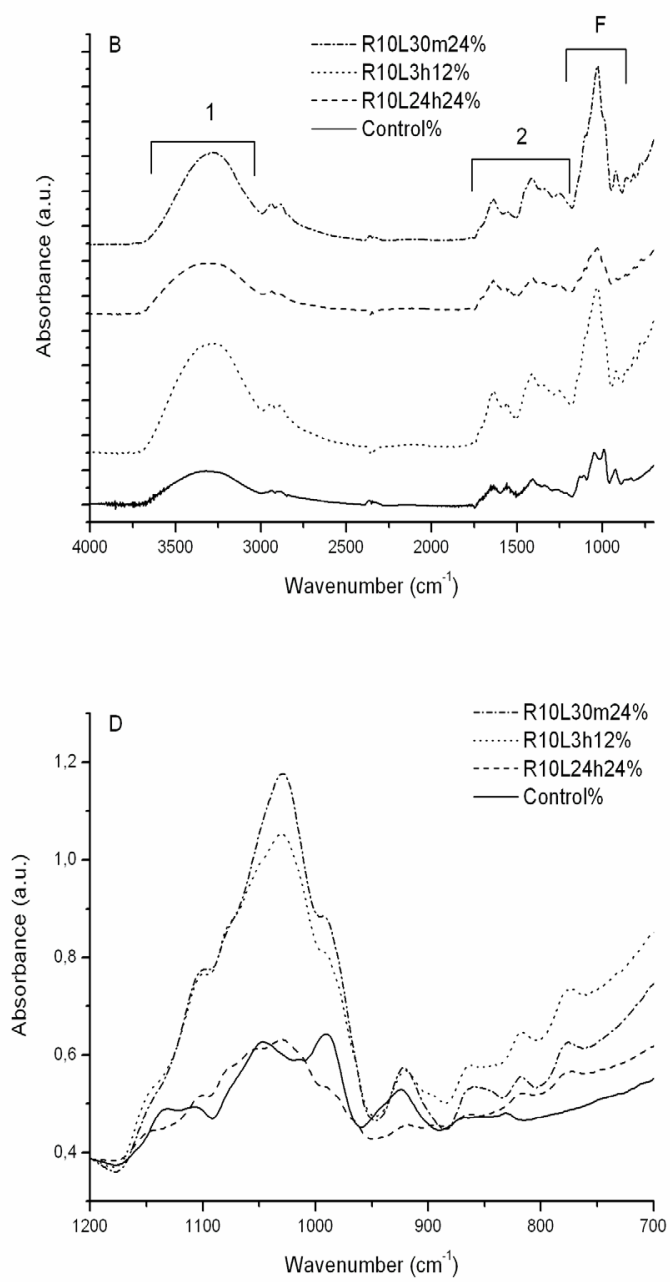

Fig. 3. The FT-MIR spectra $\left(4000-700 \mathrm{~cm}^{-1}\right)$ of the sugar beet juice obtained by enzymatic treatment $[\mathrm{RPL}(\mathrm{A})$ and R10L (B)] and without enzymatic treatment (control). Three specific regions 1, 2 and $\mathrm{F}$ are marked. Details of peaks in the specific fingerprint region (F) (1200-700 $\left.\mathrm{cm}^{-1}\right)$ in experimental samples against control [RPL (C) and R10L (D)]. For sample codes see Tab. 1.

FT-MIR spectra and fingerprint regions specific to sugar beet juice obtained with and without enzymatic treatment

In the present experiment it has been recorded a number of 21 FT-MIR spectra from the sugar beet juices obtained from puree, with or without enzymatic treatment. The specific FT-MIR spectra $\left(4000-700 \mathrm{~cm}^{-1}\right)$ for both enzymes are shown (Fig. $3 \mathrm{~A}$ and $3 \mathrm{~B}$ ), as well the fingerprint regions $\left(1200-700 \mathrm{~cm}^{-1}\right)$ after enzymatic treatment, comparing with control (Fig. 3C and 3D).

The spectra of sugar beet juice obtained with/without enzymatic treatment show three absorption regions: $3700-2850 \mathrm{~cm}^{-1}(1), 1800-1200 \mathrm{~cm}^{-1}(2)$ and a fingerprint region, $1200-700 \mathrm{~cm}^{-1}(\mathrm{~F})$. The first region, marked 1 , correspond to water and $\mathrm{OH}$ absorption frequencies, and to stretching vibrations of- $\mathrm{C}-\mathrm{H}$ inside $\mathrm{CH}_{3}$ or $\mathrm{CH}_{2}$ groups. The region 2 corresponds to carbonyl-specific absorptions $\left(1700-1500 \mathrm{~cm}^{-1}\right)$. The third region corresponds to the fingerprint region $(F)$ of carbohydrates specific to sugar beet. As can be seen in Fig. 3B, this region is different in case of sample treated with RPL and R10L. The FT-MIR spectra of samples obtained after enzymatic treatment with RPL shows two specific peaks in this region, 1039 and $991 \mathrm{~cm}^{-1}$, similar peaks as for control, while in the case of samples treated with R10L, it has been observed just one peak, around $1030 \mathrm{~cm}^{-1}$.

Other author (Kameoka et al., 1998) noticed many peaks in this region, attributed to $\mathrm{C}=\mathrm{O}$ and $\mathrm{C}-\mathrm{OH}$ stretching modes, which overlapped each other. These peaks depend on the sugar structure and on the interaction between the sugar molecules and their environments.

Thus, it was possible to identify the peaks characteristic to glucose, fructose, sucrose and galacturonic acid in sugar beet juice, in accordance with peaks observed in pure carbohydrates (Fig. 1). The peaks recorded at 1033, 1063 and $995 \mathrm{~cm}^{-1}$ were considered for the evaluation of hydrolytic activity and the rate of glucose, fructose and sucrose release, respectively. For galacturonic acid quantification in the samples, it has been considered the peaks area of the region $1500-700 \mathrm{~cm}^{-1}$. 


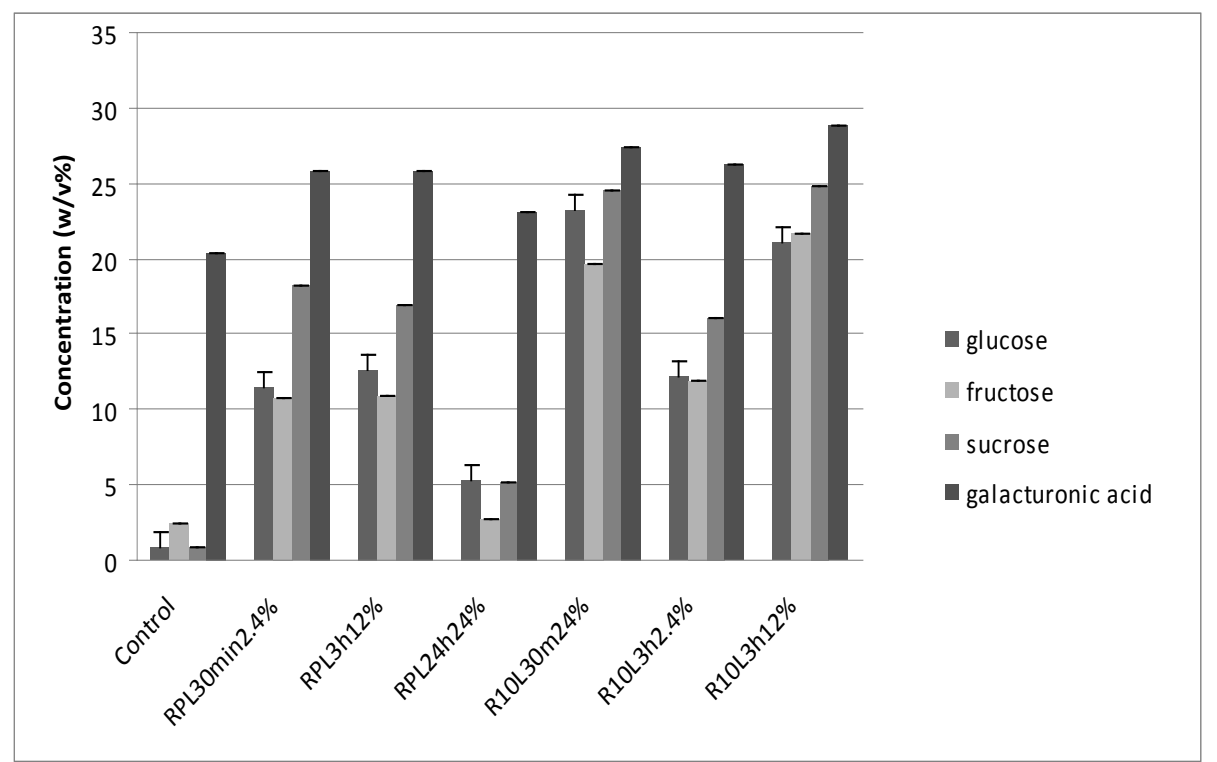

Fig. 4. Comparative representation of glucose (expressed by a peak at $1033 \mathrm{~cm}^{-1}$ ), fructose (expressed by a peak at 1063 $\mathrm{cm}^{-1}$ ), sucrose (expressed by a peak at $995 \mathrm{~cm}^{-1}$ ) and galacturonic acid (expressed by a peak area in the region 1500-700 $\mathrm{cm}^{-1}$ ) concentrations ( $\mathrm{x} \pm \mathrm{SD}$, expressed in $\mathrm{g} / 100 \mathrm{ml}$ juicereleased after enzymes treatment), against control

Quantitative evaluation of glucose, fructose, sucrose and galacturonic acid after enzymatic hydrolysis

Using the data obtained from the calibration curves of glucose, fructose, sucrose and galacturonic acid, it has been calculated the concentrations of these carbohydrates in sugar beet juice after enzymatic treatment (for the most specific samples) and without enzymatic treatment. For glucose, fructose and sucrose it has been considered the characteristic intensity of each peak $\left(1033 \mathrm{~cm}^{-1}\right.$ for glucose, $995 \mathrm{~cm}^{-1}$ for sucrose and $1063 \mathrm{~cm}^{-1}$ for fructose). The concentration of galacturonic acid was calculated based on calibration curve obtained from peak areas on fingerprint region of galacturonic acid $\left(1500-700 \mathrm{~cm}^{-1}\right)$.

As can be seen in Fig. 4, after the enzymatic treatment the concentrations of all compounds (glucose, fructose, sucrose and galacturonic acid) increase considerably in comparison with the control. The higher concentration of glucose was obtained in the sample treated with a concentration of $24 \% \mathrm{R} 10 \mathrm{~L}$ and incubation time of $30 \mathrm{~min}$ (R10 L $30 \mathrm{~m} 24 \%$ ), while the lower concentration was obtained in the sample treated with RPL (24 h, 24\%) (RPL $24 \mathrm{~h} 24 \%$ ). Fructose, sucrose and galacturonic acid were released at higher concentrations in samples treated with R10L for three hours at a concentration of $12 \%$ (R10 L 3h 12\%) (Fig. 4).

Comparing the activity of the Rohament PL at the three concentrations $(2.4 \%, 12 \%$ and $24 \%)$ and three incubation times ( $30 \mathrm{~min}, 3 \mathrm{~h}$ and $24 \mathrm{~h}$ ), it has been observed the optimum enzyme activity at $2.4 \%$ and incubation time of $30 \mathrm{~min}$. This suggests that Rohament PL had a higher rate activity, being also very specific. In the case of
Rohapect $10 \mathrm{~L}$, the optimum acivity appears at $12 \%$, and optimum time of 3 hours. Comparing these two enzymes, it has been observed that Rohament PL had higher activity, optimum in $30 \mathrm{~min}$, and best affinity to the substrate, at $2.4 \%$, while Rohapect $10 \mathrm{~L}$ needs a concentration of $12 \%$. Regarding the enzymes efficiency, expressed by released hidrolysis products, the high-efficiency enzyme was Rohapect 10 L.

\section{Conclusions}

In the present reaserch it has been applied FT-MIR spectroscopy, a non-destructive tool and useful method, to measure the pectinolytic activity of two enzymes (Rohament PL or Rohapect 10L), on sugar beet as substrate. The measurements were based on the release of small, individual sugar like glucose, fructose, sucrose and galacturonic acid by enzymatic hydrolysis of pectins. It has been identified the specific peak intensities for glucose (at 1033 $\mathrm{cm}^{-1}$ ), fructose (at $\left.1063 \mathrm{~cm}^{-1}\right)$, sucrose $\left(\right.$ at $\left.995 \mathrm{~cm}^{-1}\right)$, and peak area for galacturonic acid $\left(1500-700 \mathrm{~cm}^{-1}\right)$, and based on these data, it has been calculated the concentrations of each sugar. It has been identified as well the differences among the two enzymes activity, specifically their optimum concentration and best hydrolysis timing.

FT-MIR spectroscopy allows accurate glucose, fructose, sucrose and galacturonic acid concentration determination. Actually, FT-infrared spectroscopy is a versatile method, to be used for the simultaneous determination of a large variety of compounds present in different biological samples. Validation of this method using HPLC analysis is also underway for a more accurate quantification. 
104

\section{References}

Baciu IE, Jordening HJ (2004). Kinetics of galacturonic acid release from sugar-beet pulp. Enz Microb Technol 34:505512.

Chiş A, Fetea F, Taoutaou A, Socaciu C (2010). Application of FT-MIR spectroscopy for a rapid determination of some hydrolytic enzymes activity on sea buckthorn substrate. Rom Biotechnol Lett 15(6):5738-5744.

Fernandez K, Agosin E (2007). Quantitative analysis of red wine tannins using Fourier Transform Mid-Infrared spectrometry. J Agric Food Chem 55:7294-7300.

Foster BL, Dale BE, Doran-Peterson JB (2001). Enzymatic hydrolysis of ammonia-treated sugar beet pulp. Appl Biochem Biotechnol 93:269-282.

Kacurakova M, Capek P, Sasinkova V, Wellner N, Ebringerova A (2000). FT-IR study of plant cell wall model compounds: pectic polysaccharides and hemicelluloses. Carbohydr Polym 43:195-203.

Kameoka S, Chafik T, Ukisu Y, Miyadera T (1998). Role of organic nitro compounds in selective reduction of $\mathrm{NO}_{\mathrm{x}}$ with ethanol over different supported silver catalysts. Catal Lett 51:11-14.

Max JJ, Chapados C (2007). Glucose and fructose hydrates in aqueous solution by IR spectroscopy. J Phys Chem A 111(14):2679-2689.

Micard V, Renard CMGC, Thibault J-F (1996). Enzymatic saccharification of the sugar-beet pulp. Enz Microb Technol 19:162-170.
Patz CD, Blieke A, Ristow R, Dietrich H (2004). Application of FT-MIR spectrometry in wine analysis. Anal Chim Acta 513:81-89.

Ramasami P, Jhaumeer-Laulloo S, Rondeau P, Cadet F, Seepujak H, Seeruttum A (2004). Quantification of sugars in soft drinks and fruit juices by density, refractometry, infrared spectroscopy and statistical methods. South Afr J Chem 57:24-27.

Rambla FJ, Garrigues S, Ferrer N, de la Guardia M (1998). Simple partial least squares-attenuated total reflectance Fourier transform infrared spectrometric method for the determination of sugars in fruit juices and soft drinks using aqueous standards. Analyst 123:277-281.

Sakamoto T, Yoshinaga J, Shogaki T, Sakai T (1993). Studies on protopectinase- $\mathrm{C}$ mode of action: analysis of the chemical structure of the specific substrate in sugar beet protopectin and characterization of the enzyme activity. Biosci Biotechnol Biochem 57:1832-1837.

Thibault J-F, Rouau X (1990). Studies on enzymic hydrolysis of polysaccharides in sugar beet pulp. Carbohydr Polym 13:116.

Urtubia A, Perez-Correa JP, Pizarro F, Agosin E (2008). Exploring the applicability of MIR spectroscopy to detect early indications of wine fermentation problems. Food Cont 19:382-388. 